\title{
PERISCOPE.
}

BY DRs. G. W. JACOBY, N, F. IBRILL, AND LOUISI, FISKE-IBRYSON,

\section{ANATOMY OF THE NERVOUS SYSTEM.}

Thl: Brain Weight in the Insane. Dr. Bartels, of Hildesheim (Algcmeinc Zitsillrift für Pschiatric, etc).

The author, after giving the literature on the subject, tabulates the findings of the brain weights of males and femalcs in ten different psychoses. Accepting the average normal weight of a healthy brain to be $1,460 \mathrm{~g}$. in males and $\mathrm{I}, 320 \mathrm{~g}$. in females (Henle and Krause), the following deviations in the various psychoses present themselves:

\begin{tabular}{|c|c|c|c|}
\hline & Matles. & Femalét. & $\begin{array}{l}\text { Avernge Weight } \\
\text { in Grammes. }\end{array}$ \\
\hline 1. Manıi.. & 27 & & 1423 \\
\hline 2. Nelancholia. & 74 & 32 & $\begin{array}{l}1288 \\
1437\end{array}$ \\
\hline 3. l'eriolical Insanity... & 23 & 95 & \\
\hline 4. I'aranoia......... & 115 & $\begin{array}{l}15 \\
62\end{array}$ & $\begin{array}{l}1255 \\
1416\end{array}$ \\
\hline 5. Cicneral Paresis. & 276 & 44 & 1353 \\
\hline 6. Acutc Delirium ......... & 5 & 2 & $\begin{array}{l}1385 \\
1325\end{array}$ \\
\hline 7. Hipileptic Insanity............ & 70 & & 1421 \\
\hline 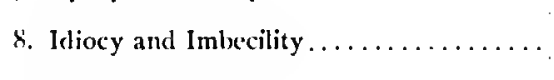 & 27 & $\begin{array}{l}32 \\
18\end{array}$ & $\begin{array}{l}1231 \\
1335 \\
1194\end{array}$ \\
\hline 9. Siccondary Dementia.............. & 181 & 124 & $\begin{array}{l}1408 \\
1263\end{array}$ \\
\hline 10. Senile bementia. & 12 & $\begin{array}{r}124 \\
6\end{array}$ & $\begin{array}{l}1203 \\
1359 \\
1200\end{array}$ \\
\hline
\end{tabular}

Too much weight ought not to be placed on these deviations; for, as the author well says, in certain groups the number of cases is not sufficient to deduce a safe estimate. In paranoia and secondary dementia, which affect the indi- 
vidual in a large proportion of cases late in life, in which the brain itself would naturally begin to diminish in weight and in which the disease itself may have been of long standing, no reliable estimate could be attained. He concludes as follows : brain.

I. All psychoses necessarily diminish the weight of the

2. This diminution depends $(a)$ on the age of the patient, (b) on the duration of the disease, (c) on the intensity of the diseasc.

a.-The diminution in weight is smallest in both sexes between twenty and thirty years of age, largest in males of seventy years of age, and in women of sixty years of age.

b. - The shorter the average duration of the disease the smaller in general is the loss in brain weight and vice iersa.

c.-The deeper the disease affects the mental life of the individual, and in the one who shows the smallest ability for mental work, the greater is the loss of brain weight, and aice acrsa.

3. The diminution in females is larger than that in males by from $\frac{1}{6}$ to 1.6 per cent.

N. E. B.

Contribution to THE MORPIIOLOgY AN1) MORPhOcilinESIS OF TIIE CRUS ClikliBRI, by G. Jelgersura (Cintralblatt fiir Noresuluilkunde, itc., Soptember 15 th and Octolice 15th.)

This embraces a short resume of the author's investigations of the brains of five idiots, in which the cortex was very much atrophied as the result of various pathological processes. Only one of the hemispheres of two of these cases showed atrophic changes, the other hemisphere in each being almost entirely normal. There were almost equal changes in both hemispheres in each of the other cases, and almost the entire cerebral cortex was destroyed by encephalitis or by meningitis. The latter cases were extreme idiots, the former two only half idiots with the somatic signs 